\title{
Subcommittee B, Basic Sciences
}

National Cancer Institute

\section{Source}

National Cancer Institute. Subcommittee B, Basic Sciences. NCI Thesaurus. Code

C19221.

Subcommittee of the Board of Scientific Counselors, NCl, which advises the Directors of the Intramural Division of the $\mathrm{NCl}$ and the Director and Deputy Director, $\mathrm{NCl}$, on a wide variety of matters concerning scientific program policy and the progress and future direction of research programs of each Division, including the evaluation of performance and productivity of each Divison, the evaluation of performance and productivity of staff scientists through periodic site visits to intramural laboratories, and evaluation and advice on the course of each Division's programs. 